\title{
Commentary II Health related interventions in organizations: stages, levels, criteria, and methodology
}

\author{
Dr. Semmer is professor of work psychology and organization at the Department of Psychology at the University of Berne
}

Lawrence Murphy and Steve Sauter (2004) have presented a concise review of key issues concerning work organization interventions. I will comment on a few points that I consider especially important, and add some thoughts of my own.

\section{Primary, secondary, and tertiary prevention}

I congratulate the authors for arguing against a common misunderstanding. Changes in work organization are often equated with primary, individual stress management with secondary and tertiary prevention. This sounds plausible, if one regards the work environment as "cause", health status as effect, and individual coping as intermediate. However, "causes" may lie both in the environment and in the individual (e.g., in health behaviors, or in social behavior that creates conflict).

If seeking to maintain a healthy status constitutes primary prevention, then focusing on individual behaviors may be primary (with healthy participants), secondary (participants who basically are well but show some symptoms), or tertiary (participants with prolonged and severe symptoms). This implies different criteria of success, which can create problems if each kind of participants is represented in a given program (Kompier \& Kristensen 2000).

\section{Levels}

The treatise of levels is another strong point of the paper. Relations to the community level are sometimes discussed (e.g., Terry \& Nunn 2002), as are influences of policy and legislation (e.g., Geurts \& Gründemann 1999), but this level is seldom included more formally. This is not just a matter of presentation. It implies that we need more research that evaluates changes in policy and legislation.

There is yet another aspect related to levels, however: The higher we get, the more indirect the effects. Individuals in stress management programs can work on the very aspects that bother them: They can learn (1) to reinterpret events (e.g., question attributions of intention regarding disliked behavior of others), (2) to cope more efficiently, or - in programs that go beyond dealing with symptoms and include aspects of problem solving (e.g., Bunce \& West 1996; Meichenbaum 1993) - (3) to induce changes in the work environment. Such programs can specifically address individual problems, and build resources for dealing with them. They should, therefore, have a good chance of success, and they actually do (e.g., Kaluza 1997).

At the other end, activities such as legislation cannot do much more than provide incentives, or constraints. These can be dealt with in many ways. Laws may be enforced less strictly because the company that pollutes a river also creates jobs. Incentives may have unintended side effects - as when workers who bend safety rules without causing an accident may be praised for being very productive. Obligations may be interpreted in terms of the letter of the law, or its spirit. The effects of policy interventions therefore are often difficult to predict, due to the creativity of the actors involved in complying with, or working around, the rules.

Organizational interventions are in between. As Murphy and Sauter mention, there is no ground for enthusiasm concerning the success of this type of intervention. It is worth mentioning, however, that very few have found adverse effects. Of course, having null effects is not enough, but a mixture of no effect and success is certainly more promising than would be a mixture of positive and negative effects. 
Organizational interventions vs person-centered interventions are, however, difficult to compare. Going beyond the individual level introduces additional elements that make potential effects increasingly indirect. When work is redesigned, each participant faces individual challenges. In addition, however, reactions of other participants come in, who might support or resist the change, and the environment reacts, as when a "pilot" group evokes envy. Furthermore, resources gained may be offset by increased demands (a frequent complaint in autonomous working groups, Antoni 1997; Semmer 2003).

These considerations, if correct, have several implications. At higher levels, (1) the number of elements that have to be considered increases, (2) the likelihood that positive change will be offset by other forces grows, reducing (3) the probability of success for a project. Furthermore, (4) the probability that there will be both "winners" and "losers" is likely to be enhanced.

\section{Criteria for success}

The arguments just presented call for a stronger focus on the balance of positive vs null, or even negative, outcomes: Does improvement for some justify no effect (or even resentment) in others - because, for instance, there are considerably more "winners", or because their initial position was particularly problematic? Positive effects for everybody may be unlikely, given that processes in a sub-system may be dysfunctional for the organization yet very functional for that sub-system (e.g., privileges). The call for subgroup analyses therefore seems well taken.

As mentionted by Murphy and Sauter with regard to worklife balance, effects may even be diverse within individuals, much like side-effects of medical drugs. Interventions may improve some outcomes (e.g., job satisfaction) but not others (e.g., stress symptoms). We may have to ask, for instance, if higher satisfaction, due to enhanced complexity and control, is worth the additional demands that may result from increased complexity (Campion 1988). To take the argument even further: Harsh conditions may, at the same time, be the basis for stress symptoms and for pride (Meara 1974). Workers have resisted reducing stressful aspects of their work, arguing that "this is a steel plant and not a girls' boarding school" (Slesina et al. 1998: 201).

All this amounts to asking whether a change has more advantages than disadvantages, rather than whether it is "good" or not (see Semmer 2003).

To complicate things further: Symptoms may be specific to individuals (Steptoe 2001). Some suffer primarily from sleeplessness, others from stomach aches, or social anxiety.
Interventions leading to improvement in everybody's "preferred" symptom are successful, yet might not yield significant improvements in mean values. Individualized measures seem promising for capturing such effects.

\section{Financial returns}

Murphy and Sauter argue for a broader range of measures, including economic outcomes, such as absenteeism, or health care utilization. I agree, but I warn against the expectation that we will be able to convince management by showing that interventions pay off. Human decision-making, including decisions in organizations, often does not follow sound and rational principles in the economic interest of the organization (cf. Halpern \& Stern 1998). Certainly, the widespread disinterest in evaluation studies does not argue for a strictly economic standpoint (see Cascio 2000; Terborg 1998). On the positive side, many managers who support health programs do not put financial considerations first but see health and well-being, or "morale" as goals in their own right (Terborg 1998; U.S. Department of Health and Human Services 1993). Of course, documenting financial effects of interventions may be helpful, but often it will not "do the job". We should therefore not lose sight of the need to build a relationship of professional trust. The literature on organizational development has recognized this for a long time. And many authors emphasize the social skills needed for being an effective change agent (Porras \& Robertson 1992). It seems to me that the acceptance by organizational members in terms of professional competence as well as personal integrity is no less important than data on financial returns. These aspects deserve more attention than they have received so far.

\section{Methodology}

There is no need to repeat the call for stronger research designs. Rather, I want to emphasize the need for documentation and measurement. Interventions often are described in rather general, sometimes even somewhat anecdotal, terms. I think that many things could be measured regularly - some with short questionnaires (e.g., trust in management, satisfaction with meetings), others by observation (e.g., participation in meetings, signs of management commitment). Such data may allow to link specific developments (e.g., changes in participation) to specific events (e.g., a manger leaving the company), much in the logic of time series. Even where optimal designs are not possible, such systematic measurement, observation, and documentation can be done. That should become our standard.

Norbert K. Semmer 


\begin{abstract}
References
Antoni CH (1997). Soziale und ökonomische Effekte der Einführung teilautonomer Arbeitsgruppen - eine quasi-experimentelle Längsschnittstudie. Ztschr Arb Organisationspsychol 41:313-42.
\end{abstract}

Bunce D, West MA (1996). Stress management and innovation interventions at work. Human Relations 49: 209-32.

Campion MA (1988). Interdisciplinary approaches to job design: a constructive replication with extensions. J Appl Psychol 73: 467-81.

Cascio WF (2000). Costing human resources. $4^{\text {th }}$ ed. Cincinnati, OH: South Western College Publishing.

Geurts SAE, Gründemann RWM (1999). Workplace stress and stress prevention in Europe. In: Kompier MAJ, Cooper CL, eds. Preventing stress, improving productivity. London: Routledge: 9-32.

Halpern JJ, Stern RN, eds. (1998). Debating rationality: nonrational aspects of organizational decision making. Ithaca, NY: Cornell University Press.

Kaluza $G$ (1997). Evaluation von Stressbewältigungstrainings in der primären Prävention - eine Metaanalyse (quasi-)experimenteller Feldstudien. Ztschr Gesundheitspsychol 5: 149-69.
Kompier MAJ, Kristensen TS (2000). Organizational work stress interventions in a theoretical, methodological and practical context. In: Dunham J, ed. Stress in the workplace: past, present and future. London: Whurr Publishers: 164-90.

Meara $H$ (1974). Honor in dirty work: the case of American meat cutters and Turkish butchers. Sociol Work Occup 1: 259-83.

Meichenbaum D (1993). Stress inoculation training: a 20-year update. In: Lehrer PM, Woolfolk $\mathrm{RL}$, eds. Principles and practice of stress management. $2^{\text {nd }}$ ed. New York, NY: Guilford: 373-406.

Murphy LR, Sauter SL (2004): Work organization interventions: state of knowledge and future directions. Soz Praventiv Med 49: 79-86.

Porras JI, Robertson PJ (1992). Organizational development. In: Dunnette MD, Hough LM, eds. Handbook of industrial and organizational psychology. Palo Alto, CA: Consulting Psychologists Press: vol. 3: 719-822.

Semmer NK (2003). Job stress interventions and organization of work. In: Tetrick LE, Quick JC, eds. Handbook of occupational health psychology. Washington, DC: American Psychological Association: $325-53$.

Slesina W, Beuels FR, Sochert R (1998). Betriebliche Gesundheitsförderung: Entwicklung und Evaluation von Gesundheitszirkeln zur Prävention arbeitsbedingter Erkrankungen. Weinheim: Juventa.
Steptoe A (2001). Psychophysiological bases of disease. In: Johnston DW, Johnston M, eds. Health psychology. Amsterdam: Elsevier: vol. 8: 39-78.

Terborg JR (1998). Health psychology in the United States: a critique and selective review. Appl Psychol 47: 199-217.

Terry P, Nunn M (2002). Connecting the workplace to the community. In: O'Donnell MP, ed. Health promotion in the workplace. $3 \mathrm{rd}$ ed. Albany, NY: Delmar: 575-89.

U.S. Department of Health and Human Services (1993). 1992 National survey of worksite health promotion activities: summary. Am J Health Prom 7: 451-64.

\author{
Address for correspondence \\ Prof. Dr. Norbert K. Semmer \\ Institut für Psychologie \\ Arbeits- und Organisationspsychologie \\ Unitobler - Muesmattstr. 45 \\ CH-3000 Bern 9 \\ e-mail: norbert.semmer@psy.unibe.ch
}

